\title{
Jejunum and ileum blunt trauma: what has changed with the implementation of multislice computed tomography?
}

\section{Trauma contuso de jejuno e íleo: o que mudou com a implementação da tomografia computadorizada multislice?}

Raquel Oliveira Menna Barreto de Araújo1, Marina Pimentel de Matos¹, Thiago José Penachim², Bruno Monteiro Tavares Pereira³, Mario Eduardo de Faria Mantovani³, Sandro Rizoli4, Gustavo Pereira Fraga ${ }^{3}$.

\section{A}

\begin{abstract}
Objective: to evaluate the impact of the new technology of multidetector computed tomography (MDCT) in improving the accuracy and early diagnosis of BSBI. Methods: patients with blunt small bowel injuries (BSBI) grade> I were identified retrospectively and their $C T$ scans reviewed by an experienced radiologist. Clinical and tomographic findings were analyzed and patients grouped as "pre-MDCT" and "post-MDCT", according to the time of implementation of a 64-slice MDCT. Results: of the 26 patients with BSBI 16 had CT scans. Motor vehicle collision (62.5\%) was the most frequent mechanism of injury. In the pre-MDCT period, five of the 13 patients (38.5\%) had abdominal CT, and in the post-MDCT, 11 of 13 patients $(84.6 \%)$ had the exam. During pre-MDCT, all CT scans were abnormal with findings of pneumoperitoneum (60\%), free fluid (40\%) and bowel wall enhancement (20\%). In the post-MDCT group, all exams but one were abnormal and the most frequent findings were free fluid $(90.9 \%)$, bowel wall enhancement $(72.7 \%)$, and pneumoperitoneum $(54.5 \%)$. However, the rate of delayed laparotomy did not change. The mortality rate in both groups were similar, with $20 \%$ during pre-MDCT and $18.2 \%$ during post-MDCT. Conclusion: the use of MDCT in abdominal trauma in our service has increased the sensibility of the diagnosis, but has had no impact on outcome so far.
\end{abstract}

Key words: Trauma. Abdominal Injuries. Intestine, Small. Computed Tomography.

\section{INTRODUCTION}

$\mathrm{T}$ he small bowel can be injured by both penetrating trauma with disruption of the abdominal wall and blunt trauma. It is the most frequently injured viscera in penetrating abdominal trauma and currently the third most common injury following blunt trauma ${ }^{1-3}$.

Direct bowel injury or to the mesentery occurs in approximately $1 \%$ to $5 \%$ of all blunt abdominal traumas, and its incidence is increasing with the growing number of automobile crashes ${ }^{4}$. The sudden deceleration caused by the kinematics of these types of collision, associated with the compression caused by the seatbelt, stretching and pulling the bowel's attachment points, account for most injuries found. Blunt small bowel injuries (BSBI) may also be caused by sports injuries, work-related incidents and falls ${ }^{5}$. Infrequently small bowel disruption caused by explosions may occur, when the intraluminal pressure exceeds the intestinal wall tension 5 .
The diagnosis of blunt small bowel injuries(BSBI) difficulties challenging, since the physical examination, which can be sensitive at times, may also be unreliable when there are brain and spine injurieswith changes in the level of consciousness or pain perception, when the patient is intoxicated or when there are other confounding extra abdominal injuries ${ }^{6-8}$.

The delay in the diagnosis of BSBI has repeatedly been shown to increase both the morbidity and mortality of these patients $1,3,4,9$. To reduce the chances of missing these injuries a combination of different diagnostic methods are used including ultrasound (US), computed tomography (CT), diagnostic peritoneal lavage (DPL) and even diagnostic laparoscopy. However, despite the number of different diagnostic methods available, the diagnosis of BSBI is still challenging because each methods has inherent limitations and are not sensitive enough to detect all $\left.B S B\right|^{2,10,11}$.A diagnostic strategy frequently employed in emergency situations is the FAST (Focused Abdominal with Sonography

1. School of Medical Sciences, University of Campinas (Unicamp), Campinas, SP, Brazil; 2. Department of Radiology, School of Medical Sciences, University of Campinas (Unicamp), Campinas, SP, Brazil; 3. Division of Trauma Surgery, Departmentof Surgery, School of Medical Sciences, University of Campinas (Unicamp), Campinas, SP, Brazil; 4. Department of Surgery and Critical Care Medicine, University of Toronto, and Director of Trauma at St Michael's Hospital, Toronto, Canada. 
in Trauma), which can be performed early in the resuscitation (i.e. trauma room), but its diagnostic value in $\mathrm{BSBI}$ is correct in only $38 \%$ of the patients or worse since FAST is operator-dependent ${ }^{10}$.

CT scan has a high sensitivity to diagnose BSBI, ranging from 64 to $95 \%$ and an accuracy of 80 to $90 \%$, providinguseful anatomic details such as contrast extravasation and extraluminal air. The longer the time interval between trauma and the CT scan, the higher the chances of the CT scan diagnosing BSB| ${ }^{12-16}$.

The CT scan can diagnose bowel injury by both identifying an injury to the bowel or mesentery integrity or via indirect findings. The latter findings includethe presence of free fluid in the cavity without solid organ injury; stricking or focal densification of the mesentericfat; dilated bowel loops; pneumoperitoneum (sensitivity of 44 to $55 \%$ since extra intestinal barotraumas/mechanical ventilation, may also cause it); thickening of the intestinal wall; extravasation of contrast (rarely identified when no oral contrast is routinely given to trauma patients, and highly indicative of intestinal perforation) and discontinuity of the intestinal wall (rarely identified) ${ }^{4,12,15,17,18}$. Most of these findings suggest but do not establish the diagnosis of $\mathrm{BSBI}{ }^{13,19}$. A large review of literature, involvingover 275,000 patients, $13 \%$ of all $\mathrm{BSBI}$ (both small bowel and/or mesenteric injuries) had normal abdominal CT scans ${ }^{20}$.

Blunt trauma of the small bowel continues to be a diagnostic challenge due to few and non specific signs and symptoms. With the advancement of technology, and the use of multislice CT scanners, capable of performing thinner sections more quickly, with fewer motion artifacts, and allowing multiplanar reformations, it becomes relevant to study the impact of the use of such additional tests in the diagnosis of BSBI.

\section{METHODS}

Descriptive study of cases prospectively recorded in the surgery book of the Division of Trauma Surgery, Department of Surgery, School of Medical Sciences (FCM), University of Campinas (Unicamp). The study subjects were patients who had small bowel (jejunum and ileum) injuries(SBI) caused by blunt trauma, who were admitted to the Referral Emergency Unit (UER), Clinical Hospital (HC) of Unicamp and who underwent surgery between 2005 and 2012, excluding patients younger than 14 years of age (who were treated with pediatric surgery).

For each of the patients with blunt trauma injuries to the small bowel, the following information was collected: age; gender; mechanism of injury; time between trauma and admission; signs and symptoms; systolic blood pressure (SBP), Glasgow Coma Scale (GCS) on admission; additional propaedeutics performed; time between admission and surgery; severity of injury ${ }^{21}$; surgical procedure performed; the Revised Trauma Score (RTS) ${ }^{22}$, Abdominal
Trauma Index (ATI) ${ }^{23}$, Injury Severity Score (ISS) ${ }^{24}$ and TRISS 25 ; and patient outcome (discharge or death).

For additional propaedeutics, the following examinations were evaluated: simple radiography, diagnostic peritoneal lavage, ultrasound, CT and/or video laparoscopy, which may indicate signs of intestinal injury. CT may show free fluid in the cavity, pneumoperitoneum, small bowel wall thickening, blurring of the mesenteric fat and other signs that indicate injury to hollow viscera or suspected injury to other organs. All these signals were analyzed for each patient, using chart notes, images and reports available in the radiology record. Cases with SBI due to blunt trauma were reviewed with the participation of an assistant radiologist. He evaluated several exams and did not know the cases with injuries to the jejunum and ileum.

The degree of injury of the small bowel was classified according to the American Association of Surgery of Trauma (AAST) ${ }^{21}$ as: Grade I, when there was hematoma (bruise or hematoma without injury) or laceration with partial thickness, without perforation; Grade II, characterized by a laceration of less than $50 \%$ of the circumference; Grade III, laceration of more than $50 \%$ of the circumference without transection; Grade IV, transection of the small bowel; Grade V, transection of the small bowel with loss of segmental tissue or vascular injury with segmental devascularization. An extra grade was added which referred to the most serious injuries, in cases of associated bowel injuries ${ }^{21}$. Grade I injuries were excluded because they are usually found during surgery and there is no perforation of the bowel loops or contamination of the peritoneum.

As for treatment of injuries, the following surgical procedures were considered: primary suture, debridement of the borders and suturing, segmental resection and primary anastomosis, or resection and stoma.

The complications presented by patients postoperatively were recorded in order to correlate them with delays in diagnoses, in cases where the injuries initially went unnoticed by the initial CT scan. As with local complications, the following were also considered: peritonitis, intraperitoneal abscess and dehiscence (small bowel fistula) as well as general complications such as pulmonary, renal, neurological, coagulopathy, other abdominal complications and sepsis.

The study was approved by the Ethics and Research Committee of the School of Medical Science, University of Campinas (Unicamp), protocol nº 713/2006.

\section{RESULTS}

Twenty-six cases of blunt trauma with injury to the small bowel of grade>I were identified. Of the cases that initially entered the study, 13 (50\%) occurred before Abril 2009 and 13 afterwards, the time at which the CT multislice apparatus became available. CT was performed 
on 5 of the 13 cases admitted before CT multislice (38.5\%) and on 11 of the 13 cases assessed by the auxiliary equipment (84.6\%), thus these 16 patients were included in the study.

The mean age of the patients was 46.4 years, varying between 21 and 74 years, with 14 patients (87.5\%) being male. The principal cause of trauma involved with injury to the small bowel was automobile accident (62.5\% of cases, Table 1).

In the pre-multislice group, the mean time interval between injury and hospital admission was two hours and 40 minutes, ranging from 30 minutes to 6 hours and 30 minutes. In the post-multislice group, the variation was 20 minutes to 20 hours, with an average of seven hours and 50 minutes.

In $31.3 \%$ of cases, patients had abdominal pain; peritoneal irritation was reported in only one patient (6.3\%); and abrasions on the abdomen were present in $18.8 \%$ of cases, as well as signs of seat belt usage.

Among the 16 patients who underwent $C T$, this was the only additional examination, which was performed on 14 of them. One of them underwent a simple abdomen X-ray, which showed compatibility with normal findings, and, in one patient, DPL was performed, which was positive for the presence of fibers.

In three cases $(11.5 \%)$ no further tests were performed. The simple radiograph was performed on four patients and yielded positive findings in $75 \%$ of them. DPL was performed in only two cases, being 100\% sensitive. The US also showed $100 \%$ sensitivity, being performed on four patients and all four presented indirect positive findings (free fluid in the abdomen).

Computed Tomography was the most performed examination (16 patients), and provided positive findings in 16 cases according to the evaluation of the experienced radiologist. The main $\mathrm{CT}$ findings were: free fluid in the cavity in $40 \%$ of pre-multislice cases and in $90 \%$ of post-multislice cases; and pneumoperitoneum in $60 \%$ of pre-multislice cases and in $54.5 \%$ of post-multislice cases. Other signals found, only in multislice $\mathrm{CT}$, were: blurring of mesenteric fat in $72.7 \%$ of cases and thickening of the bowel wallin $54.5 \%$ (Figures 1, 2 and 3).The finding of extravasation of oral contrast did not apply in the cases of multislice CT because oral iodinated contrast was not used.

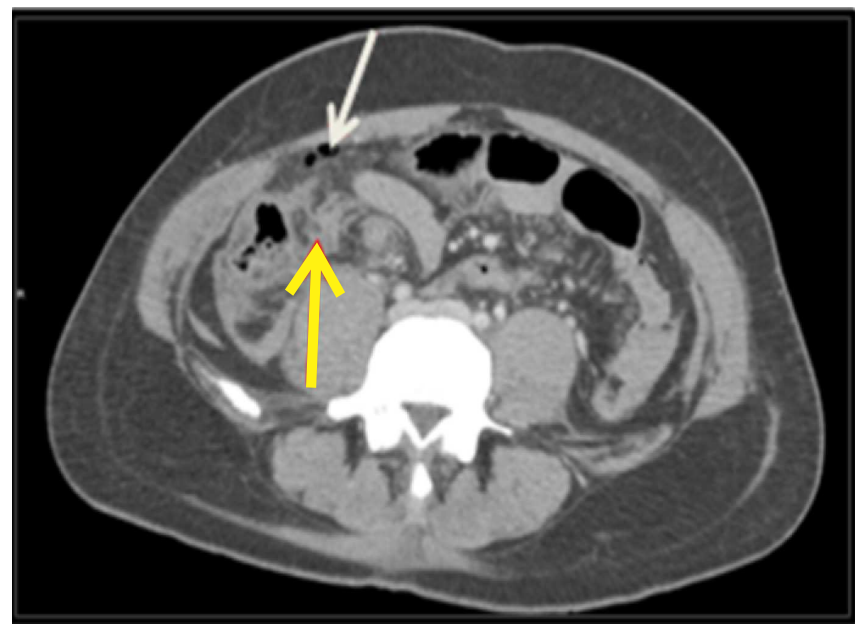

Figure 1 - Closed abdominal trauma with injury to the distal ileum. CT of the abdomen after the intravenous administration of iodinated contrast shows evidence of small bubbles of pneumoperitoneum (white arrow), as well as densification of mesenteric fat, representing edema and hematoma (yellow arrow) adjacent to the lacerated segment of the small bowel.



Figure 2 - Closed abdominal trauma with injury to the jejunumileum transition. CT of the abdomen after the intravenous administration of iodinated contrast shows evidence of a small bubble of pneumoperitoneum (white arrow), as well as densification of mesenteric fat (yellow arrow) adjacent to the injured segment of the small bowel, which has thickened walls.

Table 1 - Numbers of cases and percentages according to the causes of trauma.

\begin{tabular}{lcc}
\hline Cause of trauma & Number of cases & $\%$ \\
\hline Automobile accident & 10 & 62.5 \\
Motorcycle accident & 2 & 12.5 \\
Run over & 1 & 6.25 \\
Fall & 1 & 6.25 \\
Headed by bull & 1 & 6.25 \\
Tree trunk fall on abdomen & 1 & 6.25 \\
\hline
\end{tabular}


In all cases, a laparotomy was performed and the interval between admission and surgery was less than six hours in $80 \%$ of pre-multislice cases and in $54.5 \%$ of post-multislice cases (Figure 4).

In the pre-multislice group, four (80\%) had less than six hours between admission and surgery and one $(20 \%)$ had a delay in diagnosis and surgery occurred between 24 and 48 hours after arrival. In the post-multislice group, six of 11 (54.5\%) cases were diagnosed and went to surgery in less than six hours; two patients were operated on after between 6 and 12 and two between 12 and 24 hours. Only one patient (9.1\%) had a delay in diagnosis and surgery occurred after 24 hours. In this specific case, initial interpretation of the CT scan was normal, but after further review by an experienced radiologist, findings suggested a hollow viscera injury.

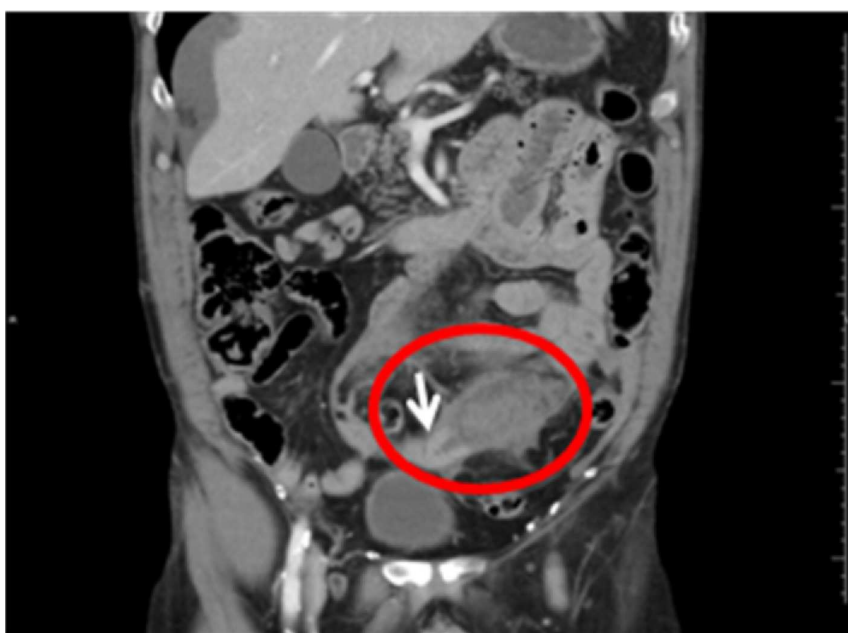

Figure 3 - Closed abdominal trauma with injury to the ileal segment. CT of the abdomen after the intravenous administration of iodinated contrast, with coronal reformation, show evidence of a large hematoma in the mesenteric fat adjacent to the injured segment of the small bowel, which has thickened walls (white arrow).

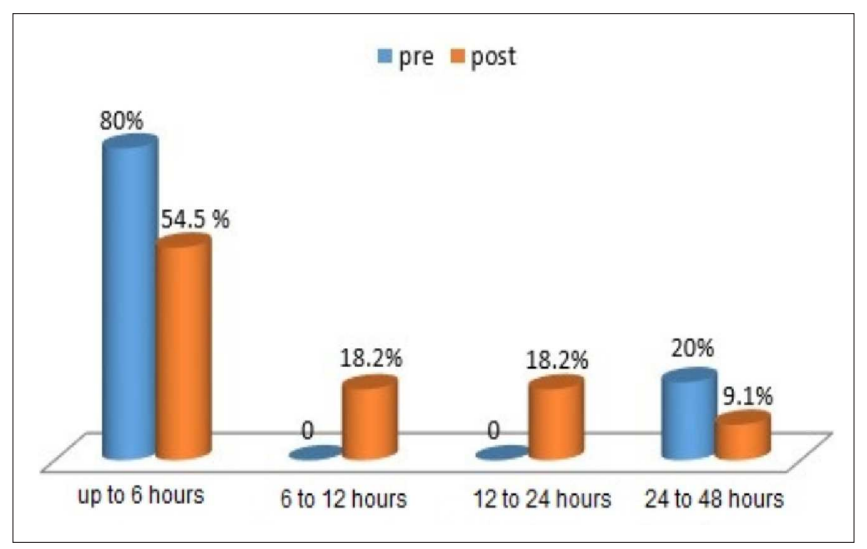

Figure 4 - Distribution of trauma cases with injuries to the small bowel, according to time elapsed between admission and surgery.
Most injuries were grade II (9 cases, 56\%), followed by grade $V$ injuries, which accounted for $38 \%$ of cases. There were no grade IV injuries and only one case of grade III (6\%).

In the pre-multislice group, all patients had RTS of 7.84 and ATI ranged from 3 to 23, with an average of 9.2, and ISS ranged from 9 to 36 with an average of 16.3. The average TRISS was 0.96 ranging from 0.85 to 0.99 . In the post-multislice group the mean RTS was 7.28 , ranging from 3.51 to 7.84 , ATI showed a mean of 8.1 (ranging from2 to 29), ISS showed an average of 15.4 (ranging from 9 to 25 ) and TRISS ranged between 0.54 and 0.99 , averaging 0.92 . The differences were not significant between the two groups.

The surgical treatment performed on most patients was simple suturing $(60 \%$ of the pre group and $55 \%$ of the post group), followed by debridement and suturing (20\% of the pre group and $9 \%$ of the post group) and resection with anastomosis (20\% ofthe pre group and $36 \%$ of the post-multislice group).

The two diagnostic groups were similar with regard to mortality. Among the pre-multislice group there was one death (20\%), which was not related to delay in diagnosis, as this patient was among those who had surgery in less than 6 hours. However, the patient had associated severe cranioencephalic trauma. Among the post-multislice cases, there were two deaths (18.2\%). In one of them, there was a delay in diagnosis because the CT scan was initially considered normal and the surgery occurred after 24 hours, and in the other case, surgery occurred in less than 6 hours but enteric fistula arose as a complication.

\section{DISCUSSION}

Several studies have put in evidence the great difficulty that still exists for rapid and accurate diagnosis of injuries to hollow viscera in blunt trauma, despite advances in diagnostic methods. CT has been the main tool in these cases and, despite major advances in CT scanners, this difficulty persists.

CT scanners have developed significantly over the past 25 years and currently there are multislice helical detectors, which produce better image quality, greater speed and fewer artifacts, as well as the possibility of multiplanar reconstructions and tridimensional views. This examination is being touted as one of the best diagnostic tools in detecting small bowel injuries.Although it is not specifically designed for hollow viscera, it indirectly allows such injuries to be identified ${ }^{4}$.

Being a referral center for trauma, HC-Unicamp receives many cases for which they need a rapid diagnosis so that surgical treatment can be carried out as soon as possible. In another study carried out in the same center, with the object of research those patients with SBI by closed trauma in the period 1994-200526, of 90 cases assessed, 23 
(25.5\%) underwent CT for diagnosis. In the present study, which took into account the period 2005-2012, 16 patients underwent CT (36\% more than in the past) with $68.7 \%$ of them using the new device. These data show not only that there was a decrease in the number of cases of blunt trauma with SBI over the years, but also an increase in the use of $C T$, which was more pronounced after the change to the new device. It is known that the multislice CT device, apart frombeing faster, provides more data and has been considered more determinant in diagnoses at the moment of decision about whether surgical interventionis required or not.

With reference to $C T$ findings that suggest injury to the hollow viscera, Brody et al. described: discontinuity of the small bowel, oral contrast outside the intestinal lumen, air outside the intestinal lumen, air in the intramural region, thickening of the bowel wall, densification of mesenteric fat and retroperitoneal and intraperitoneal free fluid ${ }^{18}$. In the cases assessed in the period $1994-2005^{26}$, the CT findings were: $82.6 \%$ had free fluid in the cavity, this being the most frequent finding, present in the current study in $40 \%$ of premultislice cases and in $91 \%$ post-multislice;60.9\% had densification of mesenteric fat, which in the current study appeared only in $72.7 \%$ of the post-multislice cases; $57.9 \%$ of the cases with thickening of the intestinal loops were also present only in post-multislice cases, 54.5\% of them; $39.1 \%$ had pneumoperitoneum, which in this study was present in $60 \%$ of the pre-multislice cases and $54.5 \%$ post-multislice; and finally $15.7 \%$ had contrast extravasation which was not identified in the current study. Similar results have been reported in literature. Bhagvan et al. obtained the following sensitivities for each tomographic finding: pneumoperitoneum, 38\%; free fluid in the cavity without injury to solid viscera, $85 \%$; free fluid, 91\%; and thickening of the bowel wall, 15\% ${ }^{27}$. Ekeh et al., in turn, found free fluid without solid organ injury in $50.9 \%$ of cases, pneumoperitoneum in $10.5 \%$ and bowel wall edema in $5.3 \%$ of assessed cases $^{16}$.

There were three $(13 \%)$ CTscans considered normal in the period 1994-200526, and in the current study (period 2005-2012), after a detailed examination by an experienced radiologist, all had findings consistent with injury to hollow viscera. One of them was initiallyconsidered normal, which ended up delaying the diagnosis. However, the eyes of the specialist (who did not know which cases had SBI or not) found more than one sign that injury was present. That is, sensitivity of the method was good, but interpretation of the signs failed. Although it is not an operator-dependent method such as the US, the use of multislice $C T$ requires experience to assess the generated images, once the $\mathrm{SBI}$ is not easily visible as solid viscera. In the study by Ekeh et al., in $19.2 \%$ of examinations, findings were not identified consistent with $\mathrm{SBI}{ }^{15}$ and in the reports by Matsushima et al., 19\% of the exam results were considered normal ${ }^{28}$.
Besides requiring expertise in the interpretation of images, the sensitivity of the method depends on the technological generation of the device. In a study by Matsushima et al., involving 67 patients, a comparison was made between the sensitivity of various generations of CT scanners, and it was shown that the 4-slice device had a sensitivity of $80 \%$, the 16 -slice $85 \%$, the 40 -slice $93 \%$, and the lowest, with $65 \%$ wasthe 64 -slice device ${ }^{28}$. He does not explain why this occurred, saying only that the study was flawed since it was retrospective, used a small sample and generations of devices changed during the study.

Other tests that may also be used to detect injuries to hollow viscera are X-ray, US and DPL. The advantages of CT compared to DPL are: the possibility of visualizing the retroperitoneum, identifying which organ is compromised, and showing, in some cases, the amount of damage, as well as being a non-invasive exam $^{9}$. Its disadvantages include the cost and the need to transport the patient to the examination site, thus making hemodynamic stability of the patient essential ${ }^{11}$.

Among the patients studied, in addition to CT, only two of them underwent additional examinations. In one of them (pre-multislice) DPL was performed, which gave a positive diagnosis for fibers, and in another (postmultislice) an X-ray was done,which showed nothing abnormal. Of the other ten patients who had blunt trauma of the small bowel, but who did not undergo CT, only seven of them underwent additional exams. Among the cases assessed between 1994 and 200526, the additional exams were US, which was performed on $8.9 \%$ of the patients, and DPL on $28.9 \%$, which gave a positive result in $92.3 \%$ of cases. It was observed that, at our hospital, and over time, additional exams have been replaced by $C T$, which is currently the most widely used method of diagnosis.

Ruptures of the small bowel can be fatal, due to peritonitis. In some cases, especially when there is a delay in diagnosis, they can lead to sepsis from bacterial contamination, as well as cause blood loss with secondary intraperitoneal hemorrhage, significantly increasing the morbidity and mortality of these cases $13,16,18$. A delay of more than 24 hours is associated with approximately $30 \%$ of mortality ${ }^{3,15,20 .}$

With regard to the time between admission and surgery, which indirectly reflects the rapidity of the health team inindicating additional tests, as well as the speed of their implementation and interpretation of the results, there was an improvement with regard to the pre-multislice group, as in only one case cited $(9.1 \%)$ there was a delay in diagnosis. In the cases assessed in the period 1994-2004, $32 \%$ of patients were operated on in less than 6 hours, between trauma and surgery, $32 \%$ between 6 and 12 hours, $14.4 \%$ between 12 and 24 hours and $7.7 \%$ between 24 and 48 hours. A delay of greater than 48 hours between 
trauma and surgery occurred in $13.3 \%$ of the cases. In the studyby Matsushima et al., $23 \%$ of the patients were operated on in a period of time longer than 12 hours, and $28 \%$ in over five hours ${ }^{28}$.

In the cases analyzed in this study, no significant changes were observed with regard to mortality, when comparing the cases in the pre-multislice period (20\%) with those in the post-multislice (18.2\%). If compared with those cases assessed in the period from 1994 to $2005^{26}$, which was also a pre-multislice period, it was found that mortality still remained around $20 \%$. In literature, reported mortality rates are in the range of 6 to $32.6 \% \%^{3,7,20,26,28}$. According to studies in large trauma centers, delays of periods longer than 24 hours in making adiagnosis, can provoke an increase of up to $30 \%$ in the mortality of patients ${ }^{3,20}$.

It is concluded that the sensitivity of the method can be considered good, having reached, in this study, $100 \%$, since all the patients, both pre-and post-multislice, had positive findings with $C T$. In previous work, on the evaluation of trauma cases in the period 1994-200526, the sensitivity was $86.9 \%$. However this improvement in sensitivity was not reflected, in practice, in improved patient outcomes. Moreover, in an emergency situation in which the surgical approach should be defined, tomographic signs may go unnoticed and there is a need for careful evaluation for correct interpretation of the exam.

\title{
R E S U M O
}

\begin{abstract}
Objetivo: avaliar se o avanço tecnológico dos aparelhos de tomografia computadorizada (TC) melhorou a acurácia e rapidez no diagnóstico dessas lesões. Métodos: pacientes com lesão de intestino delgado grau>l (AAST-OIS) por trauma contuso foram identificados e suas imagens de TC analisadas por especialista. Foram analisados achados clínicos e tomográficos agrupando os pacientes em antes e após o uso da TC multislice 64 canais, incorporada em nosso Serviço em abril de 2009. Resultados: Dentre os 26 pacientes identificados entre 2005 e 2012, 16 realizaram TC. Acidente automobilístico (62,5\%) foi o principal mecanismo de trauma. No período pré-multislice, cinco dentre 13 pacientes (38,5\%) realizaram TC e no pós-multislice 11 de 13 (84,6\%). No grupo pré-multislice todos os exames foram alterados, sendo os principais achados pneumoperitônio (60\%), liquido livre (40\%) e espessamento da parede intestinal (20\%). No grupo pós-multislice apenas um exame foi considerado normal e os achados mais frequentes nos outros 10 casos foram: líquido livre (90,9\%), espessamento da gordura do mesentério (72,7\%) e pneumoperitônio (54,5\%). Não foi observada mudança no intervalo de tempo entre a realização de TC e a laparotomia. A mortalidade em ambos os grupos foi semelhante (20\% no pré-multislice e $18,2 \%$ no pós-multislice). Conclusão: $O$ uso de tomografia multislice aumentou a sensibilidade do diagnóstico, porém sem alteração na evolução dos pacientes.
\end{abstract}

Descritores: Trauma. Traumatismos Abdominais. Intestino Delgado. Tomografia Computadorizada.

\section{REFERENCES}

1. Fraga GP, Silva FHBS, Almeida NA, Mantovani M. Fatores preditivos de morbimortalidade no trauma de intestino delgado. Rev Col Bras Cir. 2007;34(3):157-65.

2. Burney RE, Mueller GL, Coon WW, Thomas EJ, Mackenzie JR. Diagnosis of isolated small bowel injury following blunt abdominal trauma. Ann Emerg Med. 1983;12(2):71-4.

3. Fakhry SM, Brownstein M, Watts DD, Baker CC, Oller D. Relatively short diagnostic delays ( $<8$ hours) produce morbidity and mortality in blunt small bowel injury: an analysis of time to operative intervention in 198 patients from a multicenter experience. J Trauma. 2000;48(3):408-14; discussion 414-5.

4. Yu J, Fulcher AS, Turner MA, Cockrell C, Halvorsen RA. Blunt bowel and mesenteric injury: MDCT diagnosis. Abdom Imaging. 2011;36(1):50-61.

5. Sharma OP, Oswanski MF, Singer D, Kenney $B$. The role of computed tomography in diagnosis of blunt intestinal and mesenteric trauma (BIMT). J Emerg Med. 2004;27(1):55-67.

6. Hagiwara A, Yukioka T, Satou M, Yoshii H, Yamamoto S, Matsuda $\mathrm{H}$, et al. Early diagnosis of small intestine rupture from blunt abdominal trauma using computed tomography: significance of the streaky density within the mesentery. J Trauma. 1995;38(4):630-3.

7. Robbs JV, Moore SW, Pillay SP. Blunt abdominal trauma with jejunal injury: a review. J Trauma. 1980;20(4):308-11.

8. Schenk WG 3rd, Lonchyna V, Moylan JA. Perforation of the jejunum from blunt abdominal trauma. J Trauma. 1983;23(1):54-6.
9. Allen TL, Mueller MT, Bonk RT, Harker CP, Duffy OH, Stevens MH. Computed tomographic scanning without oral contrast solution for blunt bowel and mesenteric injuries in abdominal trauma. J Trauma. 2004;56(2):314-22.

10. Motta DC, Scarpelini S. Lesões traumáticas de vísceras ocas. Medicina. 2007; 40(4):531-7.

11. Liu M, Lee $\mathrm{CH}$, P'eng FK. Prospective comparison of diagnostic peritoneal lavage, computed tomographic scanning, and ultrasonography for the diagnosis of blunt abdominal trauma. $J$ Trauma. 1993;35(2):267-70.

12. Zissin R, Osadchy A, Gayer G. Abdominal CT findings in small bowel perforation. Br J Radiol. 2009;82(974):162-71.

13. Hainaux B, Agneessens E, Bertinotti R, De Maertelaer $V$, Rubesova $E$, Capelluto $E$, et al. Accuracy of MDCT in predicting site of gastrointestinal tract perforation. AJR Am J Roentgenol. 2006;187(5):1179-83.

14. Zissin R, Konikoff F, Gayer G. CT findings of iatrogenic complications following gastrointestinal endoluminal procedures. Semin Ultrasound CT MR. 2006;27(2):126-38.

15. Ekeh AP, Saxe J, Walusimbi M, Tchorz KM, Woods RJ, Anderson $\mathrm{HL}$ 3rd, et al. Diagnosis of blunt intestinal and mesenteric injury in the era of multidetector $\mathrm{CT}$ technology-are results better? J Trauma. 2008;65(2):354-9.

16. Saku M, Yoshimitsu K, Murakami J, Nakamura Y, Oguri S, Noguchi $T$, et al. Small bowel perforation resulting from blunt abdominal trauma: interval change of radiological characteristics. Radiat Med. 2006;24(5):358-64. 
17. Shanmuganathan K, Mirvis SE, Chiu WC, Killeen KL, Hogan GJ, Scalea TM. Penetrating torso trauma: triple-contrast helical CT in peritoneal violation and organ injury--a prospective study in 200 patients. Radiology. 2004;231(3):775-84.

18. Brody JM, Leighton DB, Murphy BL, Abbott GF, Vaccaro JP, Jagminas $L$, et al. $C T$ of blunt trauma bowel and mesenteric injury: typical ûndings and pitfalls in diagnosis. Radiographics. 2000;20(6):1525-36; discussion 1536-7.

19. Breen DJ, Janzen DL, Zwirewich CV, Nagy AG. Blunt bowel and mesenteric injury: diagnostic performance of CT signs. J Comput Assist Tomogr. 1997;21(5):706-12.

20. Fakhry SM, Watts DD, Luchette FA; EAST Multi-Institutional Hollow Viscus Injury Resaerch Group. Current diagnostic approaches lack sensitivity in the diagnosis of perforated blunt small bowel injury: analysis from 275,557 trauma admissions from the EAST multiinstitutional HVI trial. J Trauma. 2003;54(2):295-306.

21. Moore EE, Cogbill TH, Malangoni MA, Jurkovich GJ, Champion HL, Gennarelli TA, et al. Organ injury scaling, II: pancreas, duodenum, small bowel, colon, and rectum. J Trauma. 1990;30(11):1427-9.

22. Champion HR, Sacco WJ, Copes WS, Gann DS, Gennarelli TA, Flanagan ME. A revision of the Trauma Score. J Trauma. 1989;29(5):623-9.

23. Borlase BC, Moore EE, Moore FA. The abdominal trauma index-a critical reassessment and validation. J Trauma. 1990;30(11):13404.
24. Baker SP, O'Neill B, Haddon W Jr, Long WB. The injury severity score: a method for describing patients with multiple injuries and evaluating emergency care. J Trauma. 1974;14(3):187-96.

25. Boyd CR, Tolson MA, Copes WS. Evaluating trauma care: the TRISS method. Trauma Score and the Injury Severity Score. J Trauma. 1987;27(4):370-8.

26. Fraga GP, Silva FH, Almeida NA, Curi JC, Mantovani M. Blunt abdominal trauma with small bowel injury: are isolated lesions riskier than associated lesions? Acta Cir Bras. 2008;23(2):192-7.

27. Bhagvan S, Turai M, Holden A, Ng A, Civil I. Predicting hollow viscus injury in blunt abdominal trauma with computed tomography. World J Surg. 2013;37(1):123-6.

28. Matsushima K, Mangel PS, Schaefer EW, Frankel HL. Blunt hollow viscus and mesenteric injury: still underrecognized. World J Surg. 2013;37(4):759-65.

Received on 10/10/2013

Accepted for publication 15/12/2013

Conflict of interest: none.

Source of funding: Scientific Initiation Scholarship from the Foundationfor Research Support of the State of São Paulo (FAPESP) to Raquel Oliveira MennaBarreto de Araújo.

\section{Corresponding author:}

Gustavo Pereira Fraga

E-mail: fragagp2008@gmail.com 